\title{
Xanthelasmata, arcus corneae, and ischaemic vascular disease and death in general population: prospective cohort study
}

\author{
(c) (1) (1) OPEN ACCESS
}

\author{
Mette Christoffersen PhD student ${ }^{1}$, Ruth Frikke-Schmidt consultant ${ }^{1}$, Peter Schnohr consultant ${ }^{2}$, \\ Gorm B Jensen professor ${ }^{23}$, Børge G Nordestgaard professor ${ }^{24}$, Anne Tybjærg-Hansen professor ${ }^{12}$
}

'Department of Clinical Biochemistry, Rigshospitalet, DK-2100 Copenhagen, Denmark; ${ }^{2}$ Copenhagen City Heart Study, Bispebjerg Hospital, DK-2400 Copenhagen; ${ }^{3}$ Department of Cardiology, Hvidovre Hospital, DK-2650 Hvidovre, Denmark; ${ }^{4}$ Department of Clinical Biochemistry, Herlev Hospital, DK-2730 Herlev, Denmark

\begin{abstract}
Objective To test the hypothesis that xanthelasmata and arcus corneae, individually and combined, predict risk of ischaemic vascular disease and death in the general population.

Design Prospective population based cohort study.

Setting The Copenhagen City Heart Study.

Participants 12745 people aged 20-93 years free of ischaemic vascular disease at baseline and followed from 1976-8 until May 2009 with 100\% complete follow-up.
\end{abstract}

Main outcome measures Hazard ratios for myocardial infarction, ischaemic heart disease, ischaemic stroke, ischaemic cerebrovascular disease, and death; odds ratios for severe atherosclerosis.

Results 563 (4.4\%) of participants had xanthelasmata and 3159 (24.8\%) had arcus corneae at baseline. During 33 years' follow-up (mean 22 years), 1872 developed myocardial infarction, 3699 developed ischaemic heart disease, 1498 developed ischaemic stroke, 1815 developed ischaemic cerebrovascular disease, and 8507 died. Multifactorially adjusted hazard/odds ratios for people with versus those without xanthelasmata were 1.48 (95\% confidence interval 1.23 to 1.79$)$ for myocardial infarction, 1.39 (1.20 to 1.60) for ischaemic heart disease, 0.94 ( 0.73 to 1.21$)$ for ischaemic stroke, 0.91 ( 0.72 to 1.15$)$ for ischaemic cerebrovascular disease, 1.69 (1.03 to 2.79) for severe atherosclerosis and 1.14 (1.04 to 1.26) for death. The corresponding hazard/odds ratios for people with versus those without arcus corneae were non-significant. In people with versus those without both xanthelasmata and arcus corneae, hazard/odds ratios were 1.47 (1.09 to 1.99) for myocardial infarction, 1.56 (1.25 to 1.94) for ischaemic heart disease, 0.87 (0.57 to 1.31) for ischaemic stroke, 0.86 (0.58 to 1.26$)$ for ischaemic cerebrovascular disease, $2.75(0.75$ to 10.1$)$ for severe atherosclerosis, and 1.09 (0.93 to 1.28) for death. In all age groups in both women and men, absolute 10 year risk of myocardial infarction, ischaemic heart disease, and death increased in the presence of xanthelasmata. The highest absolute 10 year risks of ischaemic heart disease of $53 \%$ and $41 \%$ were found in men aged $70-79$ years with and without xanthelasmata. Corresponding values in women were $35 \%$ and $27 \%$. Conclusion Xanthelasmata predict risk of myocardial infarction, ischaemic heart disease, severe atherosclerosis, and death in the general population, independently of well known cardiovascular risk factors, including plasma cholesterol and triglyceride concentrations. In contrast, arcus corneae is not an important independent predictor of risk.

\section{Introduction}

Xanthelasmata palpebrarum are sharply demarcated, yellowish flat plaques on the upper or lower eyelids, most often near the inner canthus. Xanthelasmata represent areas of macrophages containing lipids, of which the major constituent is cholesteryl esters but the exact pathophysiology is not known. ${ }^{1}$ Arcus corneae (or arcus senilis) is a grey-white-yellowish opacity located near the periphery of the cornea but separated from the limbic margin by a clear corneal zone. ${ }^{2}$ Arcus corneae represents deposits of cholesteryl ester rich lipid particles, which are thought to be selectively trapped in the extracellular matrix in the stroma of the cornea. ${ }^{2}$ Although xanthelasmata and arcus corneae both consist mainly of cholesteryl esters, on average half of people presenting with xanthelasmata and arcus corneae have relatively low lipid concentrations. ${ }^{13}$

For both xanthelasmata and arcus corneae, lipids originate from plasma lipoproteins. Furthermore, similar mechanisms may be involved in the formation of xanthelasmata and atherosclerotic plaques, and formation of arcus corneae can be induced by experimental hypercholesterolaemia. ${ }^{34}$ These findings suggest that xanthelasmata and arcus corneae are markers of proatherogenic changes in the vessels and thus markers of atherosclerosis. Although most, ${ }^{35-12}$ but not all, ${ }^{13}{ }^{14}$ studies have 
reported increased concentrations of plasma total cholesterol or low density lipoprotein cholesterol, decreased high density lipoprotein cholesterol, or both in people with xanthelasmata, most of these case-control studies did not find any association between xanthelasmata and cardiovascular disease. ${ }^{3} 1011$ Similarly, arcus corneae is a well known sign of hyperlipidaemia, and some studies suggest that arcus corneae is a risk factor for cardiovascular disease, ${ }^{23}$ 15-18 although a recent study showed that this association was mainly due to an association between arcus corneae and increasing age. ${ }^{19}$ Probably because of these inconsistent results, xanthelasmata and arcus corneae are often considered benign phenomena and may not elicit further examination. However, large prospective studies examining the question of whether xanthelasmata and arcus corneae in themselves predict risk of ischaemic vascular disease and death in the general population are lacking. This is clinically important, because the visual diagnosis of xanthelasmata and arcus corneae is easy and inexpensive and can be made even in settings without access to blood samples for lipid profiles.

We tested the hypothesis that xanthelasmata and arcus corneae, individually and combined, predict risk of myocardial infarction, ischaemic heart disease, ischaemic stroke, ischaemic cerebrovascular disease, severe atherosclerosis, and death in the general population. We studied 12745 participants from the Copenhagen City Heart Study cohort, of whom 563 (4.4\%) had xanthelasmata and $3159(24.8 \%)$ had arcus corneae at baseline, and followed them from 1976-8 until May 2009.

\section{Methods}

\section{Participants}

The Copenhagen City Heart Study is a prospective cardiovascular study of the Danish general population started in 1976-8 with follow-up examinations in 1981-3, 1991-4, and 2001-3. We invited 19329 white women and men of Danish descent stratified into age groups of five years from 20 years to 80 years or older and drawn randomly from the Copenhagen Central Person Registry. Data came from a self administered questionnaire, a physical examination, and blood samples. Staff checked all questionnaires during the examination in collaboration with the participant. ${ }^{20}$

Of those participants invited, 14223 (74\%) attended and we included 12745 (66\%) people for whom complete information on all relevant variables including xanthelasmata and arcus corneae were available at baseline. We followed up participants from baseline at the 1976-8 examination to the end of May 2009 by using their unique Central Person Register number. Follow-up time was $100 \%$ complete, with no participants lost to follow-up.

\section{Xanthelasmata and arcus corneae}

Trained nurses or medical laboratory technicians, who were unaware of the participants' risk and disease profile, determined the presence of xanthelasmata and arcus corneae by careful visual inspection of the eyelids and the cornea during the physical examination.

\section{Ischaemic heart disease, ischaemic cerebrovascular disease, and death}

We collected and verified diagnoses of myocardial infarction and ischaemic heart disease (ICD-8 (international classification of diseases, 8th revision) codes 410 and 410-414; ICD-10 codes I21-I22 and I20-I25) by reviewing all hospital admissions and diagnoses entered in the national Danish Patient Registry, all causes of death entered in the national Danish Causes of Death Registry, and medical records from hospitals and general practitioners. We defined ischaemic heart disease as fatal or non-fatal myocardial infarction or characteristic symptoms of angina pectoris, including revascularisation procedures ${ }^{21}$; death from other causes led to censoring. We determined time to ischaemic heart disease from the date of study entry until the first date of a diagnosis of either myocardial infarction or angina pectoris. Diagnosis of myocardial infarction followed the changing definitions over time. After 2000, the diagnosis was based on: either typical rise and fall of biochemical markers of myocardial necrosis (troponin or creatine kinase MB) with at least one of ischaemic symptoms, development of pathological $\mathrm{Q}$ waves on the electrocardiogram, and electrocardiographic changes indicative of ischaemia or coronary artery intervention; or pathological findings of an acute, healed, or healing myocardial infarction, ${ }^{22}$ with later changes as indicated. ${ }^{23}$

We gathered potential cases with ischaemic cerebrovascular disease, including ischaemic stroke, from the national Danish Patient Registry and the national Danish Causes of Death Registry (ICD-8 codes 431-438; ICD-10 codes I60-I69, G45). We requested hospital records, and experienced neurologists reviewed all potential cases. We validated possible stroke events (in patients admitted to hospital as well as non-admitted) by using the World Health Organization's definition of stroke: an acute disturbance of focal or global cerebral function with symptoms lasting longer than 24 hours or leading to death with presumably no other reasons than of vascular origin. To distinguish between infarction (ischaemic stroke), intracerebral haemorrhage, and subarachnoid haemorrhage, a computed tomography or magnetic resonance scan, autopsy, spinal fluid examination, or surgical description was needed. The event was diagnosed as an ischaemic stroke if the scan did not show an infarction or haemorrhage but the person had symptoms that met the criteria of the definition of stroke. We did not apply the diagnosis of stroke in cases in which a scan showed signs of previous cerebrovascular disease but no history of any symptoms was present. The diagnostic criteria for ischaemic cerebrovascular disease were ischaemic stroke, transient ischaemic attack (focal neurological symptoms lasting less than 24 hours), or amaurosis fugax (transient blindness in one eye only).

Information on date of death came from the national Danish Central Person Registry, which is $100 \%$ complete.

\section{Severe atherosclerosis}

Ankle brachial index, a drop in blood pressure in the legs that predicts severe atherosclerosis, ${ }^{24-27}$ was determined in the 2001-3 examination of the Copenhagen City Heart Study in 2773 participants who had also participated in the baseline examination (1976-8) and had complete information on all relevant variables including xanthelasmata and arcus corneae. A standard brachial systolic and diastolic blood pressure was recorded on both arms, and systolic ankle blood pressure of the posterior tibial artery on both legs was obtained by Doppler (Huntleigh Mini Dopplex Doppler D900, Huntleigh, UK). The ankle brachial index was the lowest ankle systolic blood pressure divided by the highest brachial systolic blood pressure. Severe atherosclerosis was an ankle brachial index below 0.9 .

\section{Lipid profile}

Enzymatic methods (Boehringer Mannheim, Mannheim, Germany) were used on fresh plasma samples to measure plasma concentrations of total cholesterol, triglycerides, and high 
density lipoprotein cholesterol, the last after precipitation of lipoproteins containing apolipoprotein B. Low density lipoprotein cholesterol was calculated by using the Friedewald equation if triglycerides were below $4 \mathrm{mmol} / \mathrm{L}(<354.0 \mathrm{mg} / \mathrm{dL})$ and measured directly at higher triglyceride concentrations (Thermo, Helsinki, Finland). ${ }^{28}$ Apolipoproteins A1 and B and lipoprotein(a) were measured by using turbidimetry (Boehringer Mannheim, Mannheim, Germany; DAKO A/S, Glostrup, Denmark, and Thermo, Helsinki, Finland). ${ }^{29}$

\section{Other covariates}

Body mass index was calculated as weight in kilograms divided by height in metres squared. We defined hypertension as use of antihypertensive drugs, a systolic blood pressure of more than $140 \mathrm{~mm} \mathrm{Hg}$, or a diastolic blood pressure of more than $90 \mathrm{~mm}$ $\mathrm{Hg}$. We defined diabetes mellitus as self reported disease, use of insulin or oral hypoglycaemic agents, or non-fasting plasma glucose concentrations of more than $11 \mathrm{mmol} / \mathrm{L}$ (>198 mg/dL). Smoking status was positive for active smokers. Pack years' smoking was the accumulated exposure to smoking calculated from the questionnaires and categorised as 0 pack years (non-smokers and smokers who had smoked less than one pack of cigarettes a day for one month), $<10$ pack years

(corresponding to one pack of cigarettes a day for between one month and 10 years), 10 to 20 pack years (corresponding to one pack of cigarettes a day for between 10 and 20 years), and $\geq 20$ pack years (corresponding to one pack of cigarettes a day for 20 years or more). Regular alcohol consumers drank alcohol at least twice weekly, and light drinkers consumed alcohol less often. We defined physical inactivity as leisure time activity of less than four hours weekly. Women reported menopausal status and use of hormonal replacement therapy. We considered a family history of ischaemic vascular disease to be at least one parent with a previous myocardial infarction or ischaemic stroke. We included education and income as markers of the socioeconomic status of the participants. We dichotomised education as less than eight years of education versus at least eight years of education. We dichotomised income as a 1976-8 income of less than 10000 Danish kroner (£1186; €1340; \$1934) per month versus at least 10000 Danish kroner per month.

\section{Statistical analyses}

We used Stata version 10.1 for all analyses. We considered two sided probability values less than 0.05 to be significant. We used the Mann-Whitney $U$ test or Pearson $\chi^{2}$ test in comparisons of two groups. We plotted cumulative incidences of myocardial infarction, ischaemic heart disease, and death as a function of age by using Kaplan-Meier curves and determined differences between people with and without xanthelasmata by using log-rank tests. We have not shown Kaplan-Meier curves for ischaemic stroke and ischaemic cerebrovascular disease as a function of xanthelasmata or all end points for arcus corneae owing to modest or no differences in cumulative incidences. We used Cox proportional hazards regression models, with age as the time scale and left truncation (delayed entry), to estimate hazard ratios for myocardial infarction, ischaemic heart disease, ischaemic stroke, ischaemic cerebrovascular disease, and death as a function of xanthelasmata and arcus corneae, individually and combined. When age is used as the time scale, this implies that age is automatically adjusted for. Additional adjustments were for sex or multifactorially for sex, total cholesterol, triglycerides, body mass index, hypertension, diabetes mellitus, pack years' smoking, alcohol consumption, physical inactivity, postmenopausal status and use of hormonal replacement therapy, family history of ischaemic vascular disease, education, and income. We examined the assumption of linearity on the log risk scale for continuous covariates (total cholesterol, triglycerides, and body mass index) by including each covariate squared, one at a time, in the fully adjusted regression models. Because of lack of complete linearity, we included these covariates as fifths in the Cox regression model. We assessed proportionality of hazards over time by plotting

$-\ln (-\ln ($ survival $))$ versus $\ln$ (analysis time) and tested it by using Schoenfeld residuals. We found no major violations of the proportional hazards assumption. We accounted for competing risk of any death by censoring at the date of death. We used logistic regression models adjusted for the same covariates as above to estimate odds ratios for severe atherosclerosis (ankle brachial index $<0.9 v \geq 0.9$ ) as a function of presence or absence of xanthelasmata and arcus corneae, individually and combined.

We evaluated interaction between presence or absence of xanthelasmata and other cardiovascular risk factors (sex, age $<55$ years $v \geq 55$ years, total cholesterol $<50$ th centile $v \geq 50$ th centile, triglycerides $<50$ th centile $v \geq 50$ th centile, body mass index $<25 v \geq 25$, hypertension yes/no, diabetes mellitus yes/no, and smoking yes/no) on risk of myocardial infarction, ischaemic heart disease, and death by the inclusion of interaction terms for two factors between xanthelasmata and other risk factors one at a time in the Cox regression model, using a likelihood ratio test between models excluding and including the interaction term. For the test of interaction with age, we used years of follow-up instead of age as the time scale, analysing time to event. We have not shown stratification and test of interaction for ischaemic stroke and ischaemic cerebrovascular disease as a function of xanthelasmata or all end points for arcus corneae owing to lack of effect on overall risk estimates.

We estimated absolute 10 year risks of myocardial infarction, ischaemic heart disease, and death by presence or absence of xanthelasmata and age ( $<40$ years, $40-49$ years, $50-59$ years, 60-69 years, 70-79 years) by using the regression coefficients from a Poisson regression model for women and men separately and presented them as estimated incidence rates (number of events per 10 years) in percentages. ${ }^{29}$ We have not shown absolute 10 year risks of ischaemic stroke and ischaemic cerebrovascular disease as a function of xanthelasmata or all end points for arcus corneae owing to lack of effect on overall risk estimates.

\section{Results}

Table $1 \Downarrow$ shows baseline characteristics of people from the general population by presence of xanthelasmata and arcus corneae. The prevalence of xanthelasmata was $4.4 \%$ and similar in women and men. The prevalence of arcus corneae was $24.8 \%$ overall but was lower in women than in men $(20.1 \% v 30.2 \%$; $\mathrm{P}<0.001)$, as previously reported. ${ }^{15}$

No participants were taking lipid lowering treatment at baseline in 1976-8, as this treatment was generally not implemented in Denmark until publication of the Scandinavian Simvastatin Survival Study in $1994 .{ }^{30}$ In total, less than $2 \%$ were taking lipid lowering treatment during follow-up after $1994 .^{31}$

\section{Lipid profile}

In people with xanthelasmata or arcus corneae at baseline, plasma concentrations of total cholesterol, low density lipoprotein cholesterol, apolipoprotein B, and triglycerides at baseline were higher than in those without these traits (figs $1 \Downarrow$ and $2 \Downarrow$ ). High density lipoprotein cholesterol and apolipoprotein A1 were lower in people with xanthelasmata than in those without xanthelasmata, and lipoprotein(a) was higher in those 
with arcus corneae than in those without arcus corneae (figs $1 \Downarrow$ and $2 \Downarrow)$.

\section{Ischaemic heart disease, ischaemic cerebrovascular disease, and death}

During a follow-up of up to 33 years (mean follow-up 22 years), 1872 participants developed myocardial infarction, 3699 developed ischaemic heart disease, 1498 developed ischaemic stroke, 1815 developed ischaemic cerebrovascular disease, and 8507 died. For myocardial infarction, ischaemic heart disease, ischaemic stroke, ischaemic cerebrovascular disease, and total death, the incidence rates in events per 10000 person years were $121,226,64,74$, and 414 in people with xanthelasmata and $65,134,53,65$, and 293 in those without xanthelasmata (table $2 \Downarrow$ ). Multifactorially adjusted (age, sex, total cholesterol, triglycerides, body mass index, hypertension, diabetes, pack years' smoking, alcohol consumption, physical activity, postmenopausal status, hormonal replacement therapy, education, income, and family history of ischaemic vascular disease) hazard ratios were 1.48 (95\% confidence interval 1.23 to 1.79 ) for myocardial infarction, 1.39 (1.20 to 1.60) for ischaemic heart disease, 0.94 ( 0.73 to 1.21 ) for ischaemic stroke, 0.91 ( 0.72 to 1.15$)$ for ischaemic cerebrovascular disease, and 1.14 (1.04 to 1.26 ) for total death (table $2 \Downarrow$ ).

For myocardial infarction, ischaemic heart disease, ischaemic stroke, ischaemic cerebrovascular disease, and total death, the incidence rates in events per 10000 person years were 110, 236, 83,101 , and 510 in people with arcus corneae and 57, 115, 47, 57 , and 247 in those without arcus corneae (table $3 \Downarrow$ ). After multifactorial adjustment, no hazard ratios remained significant.

In people with versus those without both xanthelasmata and arcus corneae, multifactorially adjusted hazard ratios were 1.47 (1.09 to 1.99) for myocardial infarction, 1.56 (1.25 to 1.94) for ischaemic heart disease, 0.87 ( 0.57 to 1.31 ) for ischaemic stroke, 0.86 (0.58 to 1.26$)$ for ischaemic cerebrovascular disease, and 1.09 ( 0.93 to 1.28 ) for total death (table $4 \Downarrow$ ). We found no interaction between xanthelasmata and arcus corneae on risk of any end point.

The cumulative incidence of myocardial infarction, ischaemic heart disease, and death was higher in people with versus those without xanthelasmata (all log-rank tests, $\mathrm{P}<0.001$ ) (fig $3 \Downarrow$ ). The median survival time (that is, the age at which $50 \%$ were still alive) was 75 years in people with xanthelasmata compared with 78 years in those without xanthelasmata $(\mathrm{P}<0.001)$.

We found statistical evidence for an interaction between xanthelasmata and sex on risk of myocardial infarction (multifactorially adjusted $\mathrm{P}=0.04$ ) and risk of ischaemic heart disease $(\mathrm{P}=0.04)$ and between xanthelasmata and age on risk of myocardial infarction $(\mathrm{P}=0.01)$ and risk of ischaemic heart disease $(\mathrm{P}=0.04)$ (fig $4 \Downarrow$ ). In women, xanthelasmata was a slightly better predictor of myocardial infarction and ischaemic heart disease than it was in men; in people aged under 55, xanthelasmata was a slightly better predictor of myocardial infarction and ischaemic heart disease than it was in those aged 55 or over.

\section{Severe atherosclerosis}

Ankle brachial index, a drop in blood pressure in the legs that predicts severe atherosclerosis, was measured at the 2001-3 examination. Of 2773 people who attended both the 1976-8 and 2001-3 examinations of the Copenhagen City Heart Study, 75 had xanthelasmata and 249 had arcus corneae at baseline, and 647 had an ankle brachial index below 0.9 indicating severe atherosclerosis (table $5 \Downarrow$ ). Mean ankle brachial index was lower in people with xanthelasmata or arcus corneae than in those without $(\mathrm{P}<0.01$; table $5 \Downarrow$, third column). Thirty-nine per cent of people with xanthelasmata had an ankle brachial index below 0.9 , indicating severe atherosclerosis, compared with $23 \%$ of those without xanthelasmata. Corresponding values were $34 \%$ and $22 \%$ in people with and without arcus corneae $(\mathrm{P}<0.01$; table $5 \Downarrow$, right column).

Multifactorially adjusted odds ratio for severe atherosclerosis in people with versus those without xanthelasmata was 1.69 (1.03 to 2.79) (table $2 \Downarrow$ ). Arcus corneae was not associated with increased risk of severe atherosclerosis (table $3 \Downarrow$ ).

\section{Absolute 10 year risk of myocardial infarction, ischaemic heart disease, and total death}

We further examined the significant associations between xanthelasmata and risk of myocardial infarction, ischaemic heart disease, and total death by calculating absolute 10 year risks. In all age groups in both women and men, absolute 10 year risk of myocardial infarction, ischaemic heart disease, and total death increased in the presence of xanthelasmata (table $6 \Downarrow$ ). The highest absolute 10 year risks of myocardial infarction of $28 \%$ and $19 \%$ were in men aged $70-79$ years with and without xanthelasmata. Equivalent values in women were $14 \%$ and $9 \%$. For ischaemic heart disease, corresponding values were 53\% and $41 \%$ in men and $35 \%$ and $27 \%$ in women. The absolute 10 year risks of total death were higher than those for myocardial infarction and ischaemic heart disease, but the absolute increase in risk in people with versus those without xanthelasmata was slightly attenuated compared with those for myocardial infarction and ischaemic heart disease.

\section{Discussion}

The principal finding of this study of 12745 people from the Danish general population followed from 1976-8 to 2009 is that presence of xanthelasmata in itself predicts risk of myocardial infarction, ischaemic heart disease, severe atherosclerosis, and death in the general population independent of well known cardiovascular risk factors, including plasma cholesterol and triglyceride concentrations. In contrast, arcus corneae is not an important independent predictor of risk. These findings are novel.

\section{Comparison with other studies}

This prospective study is substantially larger than previous studies. A study of 100 patients with xanthelasmata attending a dermatology outpatient clinic and 100 matched controls found no increased risk of cardiovascular disease associated with xanthelasmata. ${ }^{11}$ In support of our findings, xanthelasmata have previously been shown to be a predictor of future death among 1712 Italian men in a prospective study at both 25 and 30 years of follow-up. ${ }^{32}{ }^{33}$ A possible explanation for the increased risk of myocardial infarction and ischaemic heart disease as well as the reduced longevity predicted by the presence of xanthelasmata may be an increased propensity of these people to deposit cholesterol in connective tissues of the body. This could be due to increased leakage of cholesterol from the vessels, increased retention of cholesterol in the connective tissue of both the arterial intima and the dermis, increased uptake of cholesterol in macrophages, and combinations of these factors and other factors as well. ${ }^{1}$

The prevalence of xanthelasmata was similar in women and men. However, presence of xanthelasmata was a slightly better predictor of myocardial infarction and ischaemic heart disease 
in women than in men, and in those aged under 55 years compared with those aged 55 and over. This might be explained by the fact that male sex and age are both well known risk factors for myocardial infarction and ischaemic heart disease, ${ }^{20}$ so the presence of xanthelasmata just adds to this predetermined risk in men and in older people. In women, who have a smaller inherent risk of developing myocardial infarction and ischaemic heart disease, presence of xanthelasmata has a correspondingly larger predictive value. Importantly, our results show that although mean concentrations of cholesterol and triglycerides were higher in people with xanthelasmata than in those without xanthelasmata at baseline, xanthelasmata predicted similar increases in risk for myocardial infarction and ischaemic heart disease in those with concentrations of cholesterol and triglycerides below the 50th centile and at or above the 50th centile. This is a question that has been debated extensively, as most previous work has focused on differences between hyperlipidaemic and normolipidaemic people with xanthelasmata. ${ }^{67101434}$ Our results clearly establish for the first time that people with xanthelasmata have an increased risk of cardiovascular disease regardless of plasma cholesterol and triglyceride concentrations. This implies that our hypothesised increased tendency for people with xanthelasmata to deposit cholesterol in tissues is largely independent of plasma concentrations of these lipids.

We calculated the absolute 10 year risk of ischaemic heart disease in people with xanthelasmata and found that it approaches or exceeds $20 \%$ in several age groups of both sexes. People with an absolute 10 year risk of ischaemic heart disease above $20 \%$ are generally considered to be at high risk, and recommendations for treatment include both lifestyle changes and treatment to reduce low density lipoprotein cholesterol. ${ }^{35}$ The absolute 10 year risk estimates for myocardial infarction, ischaemic heart disease, and total death as a function of presence of xanthelasmata stratified for age and sex allows clinicians to use presence of xanthelasmata together with age and sex in the assessment of risk in individual patients.

Presence of arcus corneae was associated with an increased risk of myocardial infarction, ischaemic heart disease, and total death after adjustment for only age and sex. However, arcus corneae did not remain a risk predictor after multifactorial adjustment. In support of these findings, a recent prospective study with eight years of follow-up reported a trend towards a significant association between arcus corneae and cardiovascular disease after adjustment for age and sex, which disappeared after additional adjustment for well known cardiovascular risk factors. ${ }^{19}$ Thus, presence of arcus corneae seems to reflect an adverse cardiovascular risk profile-probably in particular an unfavourable lipid profile. This is supported by the higher prevalence of arcus corneae in men, who have a larger inherent risk of cardiovascular disease.

\section{Implications for clinicians and policymakers}

The results from this study suggest that xanthelasmata are a cutaneous marker of atherosclerosis independent of lipid concentrations and thus should be considered in clinical practice as an independent and additional risk factor for myocardial infarction and ischaemic heart disease. Today, most people with xanthelasmata are seen by dermatologists, when they want their xanthelasmata removed for cosmetic reasons. Because of the lack of consensus on the clinical importance of xanthelasmata, some of these people may not have been managed according to their increased risk of cardiovascular disease. The findings from our study could be of particular value in societies where access to laboratory facilities, and thus lipid profile measurement, is difficult. In this setting, presence of xanthelasmata may be a useful predictor of underlying atherosclerotic disease. An easy registration of presence of xanthelasmata along with age and sex makes it possible to assess the risk of myocardial infarction and ischaemic heart disease and thus to make sure that people at increased risk are managed accordingly with lifestyle changes and treatment to reduce low density lipoprotein cholesterol.

\section{Strengths and limitations of study}

Our study has several strengths. We studied a homogeneous white general population of $100 \%$ Danes; we had a $66 \%$ participation rate and up to 33 years of complete follow-up. For all participants, complete information on all variables was available at baseline, and we had sufficient statistical power to examine even the association between xanthelasmata and risk of ischaemic vascular disease and total death in different subgroups of our study population. Moreover, no participants were using lipid lowering treatment at baseline in 1976-8, so none of the lipid profiles of the participants are biased by effects of treatment. This makes this study unique in its ability to evaluate the association between xanthelasmata, arcus corneae, lipid concentrations, and risk of cardiovascular disease.

A limitation to the generalisability of our study is that we examined only white people. The prevalence of xanthelasmata and arcus corneae, as well as the association with risk of cardiovascular disease, may differ among different ethnicities. Therefore, our findings may not necessarily translate to populations of other ethnicities. Another limitation is that the diagnosis of xanthelasmata and arcus corneae was based on visual inspection. Overlooking mild cases of xanthelasmata and arcus corneae is of course a possibility, which could have led to an underestimation of risk of disease and death. The opposite situation-misclassification of people free of xanthelasmata and arcus corneae-is probably less likely, as both of these deposits are relatively easy to diagnose visually and the investigators were specifically trained for this. Furthermore, the prevalence of xanthelasmata and arcus corneae in our study corresponds well with previous reports in the literature. ${ }^{19}$ Finally, although we have adjusted for a large number of covariates, unmeasured confounders may still have influenced our results. In particular, low density lipoprotein cholesterol, high density lipoprotein cholesterol, lipoprotein(a), and apolipoproteins were not measured at baseline in 1976-8 and thus were not adjusted for. However, we adjusted for total cholesterol (that is, cholesterol in low density lipoprotein, high density lipoprotein, remnants, and lipoprotein(a)) and for non-fasting triglycerides. In addition, we adjusted for baseline measurements of all confounders, although some confounders may have changed during the follow-up period of up to 33 years.

\section{Conclusion}

We have shown that xanthelasmata predict increased risk of myocardial infarction, ischaemic heart disease, and total death independently of well known cardiovascular risk factors, including plasma cholesterol and triglyceride concentrations. In contrast, arcus corneae is not an important independent risk predictor.

We thank the staff and participants from the Copenhagen City Heart Study for their important contributions to our study.

Contributors: All authors contributed to the study design and had full access to all the data in the study. MC, RF-S, BGN, and AT-H analysed and interpreted the data. PS and GBJ contributed to the collection of data, through initiation of the Copenhagen City Heart Study. MC and 


\section{What is already known on this topic}

Xanthelasmata and arcus corneae are associated with increased concentrations of plasma total or low density lipoprotein cholesterol, decreased concentrations of high density lipoprotein, or both

Most previous studies have shown no associations between xanthelasmata or arcus corneae and risk of myocardial infarction and ischaemic heart disease, but the results are inconsistent, and few prospective studies exist. Consensus on the clinical importance of xanthelasmata and arcus corneae is absent

\section{What this study adds}

Xanthelasmata, but not arcus corneae, predicts increased risk of myocardial infarction, ischaemic heart disease, and total death independently of well known cardiovascular risk factors, including plasma cholesterol and triglyceride concentrations

People with xanthelasmata and relatively low lipid concentrations are at an increased risk of myocardial infarction, ischaemic heart disease, and early death, independent of their lipid profiles

Arcus corneae is not an important independent risk predictor

AT-H drafted the report (with significant contributions from all other authors). All authors have seen and approved the final version of the report. MC and AT-H are the guarantors.

Funding: This study was funded by the Research Fund at Rigshospitalet, the Lundbeck Foundation, the Danish Medical Research Council, and the Danish Heart Foundation. The sponsors had no role in the design of the study; in the collection, analysis, and interpretation of data; in the writing of the report; or in the decision to submit the article for publication. The views expressed in this paper are those of the authors and not those of any funding body or others whose support is acknowledged. Competing interests: All authors have completed the Unified Competing Interest form at www.icmje.org/coi_disclosure.pdf (available on request from the corresponding author) and declare: no support from any organisation for the submitted work; no financial relationships with any organisations that might have an interest in the submitted work in the previous three years; no other relationships or activities that could appear to have influenced the submitted work.

Ethical approval: The study was approved by institutional review boards and by Danish ethical committees (the Copenhagen and Frederiksberg committee and the Copenhagen County committee; KF-100.2039/91, KF-01-144/01, H-KF-01-144/01). Participants gave written informed consent.

Data sharing: No additional data available.

1 Bergman R. The pathogenesis and clinical significance of xanthelasma palpebrarum. $J$ Am Acad Dermatol 1994;30:236-42.

2 Fernández A, Sorokin A, Thompson PD. Corneal arcus as coronary artery disease risk factor. Atherosclerosis 2007;193:235-40.

3 Segal P, Insull W Jr, Chambless LE, Stinnett S, LaRosa JC, Weissfeld L, et al. The association of dyslipoproteinemia with corneal arcus and xanthelasma: the Lipid Research Clinics Program Prevalence Study. Circulation 1986;73:I108-18.

4 Parker F, Odland GF. Experimental xanthoma: a correlative biochemical, histologic, histochemical, and electron microscopic study. Am J Pathol 1968;53:537-65.

5 Kahán A, Kahán IL, Timár V. Lipid anomalies in cases of xanthelasma. Am J Ophthalmol 1967;63:320-5.

6 Bates MC, Warren SG. Xanthelasma: clinical indicator of decreased levels of high-density lipoprotein cholesterol. South Med J 1989;82:570-4

7 Watanabe A, Yoshimura A, Wakasugi T, Tatami R, Ueda K, Ueda R, et al. Serum lipids, lipoprotein lipids and coronary heart disease in patients with xanthelasma palpebrarum. Atherosclerosis 1981;38:283-90.

8 Ribera M, Pintó X, Argimon JM, Fiol C, Pujol R, Ferrándiz C. Lipid metabolism and apolipoprotein $E$ phenotypes in patients with xanthelasma. Am J Med 1995;99:485-90.

9 Tursen U, Eskandari G, Kaya TI, Tamer L, Ikizoglu G, Atik U. Apolipoprotein E polymorphism and lipoprotein compositions in normolipidaemic xanthelasma patients. $J$ Eur Acad Dermatol Venereol 2006;20:260-3.

10 Chan CC, Lin SJ, Hwang JJ, Sun CC, Jeng JS, Hwang BS, et al. Xanthelasma is not associated with increased risk of carotid atherosclerosis in normolipidaemia. Int $\mathrm{J}$ Clin Pract 2008;62:221-7.

11 Özdöl S, Şahin S, Tokgözoğlu L. Xanthelasma palpebrarum and its relation to atherosclerotic risk factors and lipoprotein(a). Int J Dermatol 2008;47:785-9.

12 Pedace FJ, Winkelmann RK. Xanthelasma palpebrarum. JAMA 1965;193:893-4.

13 Jónsson A, Sigfússon N. Significance of xanthelasma palpebrarum in the normal population. Lancet 1976;1:372.

14 Noël B. Premature atherosclerosis in patients with xanthelasma. J Eur Acad Dermatol Venereol 2007;21:1244-8.

15 Rifkind BM. The incidence of arcus senilis in ischaemic heart-disease: its relation to serum-lipid levels. Lancet 1965;1:312-4.
16 Klein B, Klein R, Haseman J, Maready J, Hames C. Corneal arcus and cardiovascular disease in Evans County, Georgia. Arch Intern Med 1975;135:509-11.

17 Rosenman RH, Brand RJ, Sholtz RI, Jenkins D. Relation of corneal arcus to cardiovascular risk factors and the incidence of coronary disease. N Engl J Med 1974;291:1322-4.

18 Pe'er J, Vidaurri J, Halfon ST, Eisenberg S, Zauberman H. Association between corneal arcus and some of the risk factors for coronary artery disease. $\mathrm{Br} \mathrm{J}$ Ophthalmol 1983;67:795-8.

19 Fernandez AB, Keyes MJ, Pencina M, D’Agostino R, O'Donnell CJ, Thompson PD. Relation of corneal arcus to cardiovascular disease (from the Framingham Heart Study data set). Am J Cardiol 2009;103:64-6.

20 Schnohr P, Jensen JS, Scharling H, Nordestgaard BG. Coronary heart disease risk factors ranked by importance for the individual and community: a 21 year follow-up of 12000 men and women from the Copenhagen City Heart Study. Eur Heart J 2002;23:620-6.

21 Fox K, Garcia MA, Ardissino D, Buszman P, Camici PG, Crea F, et al. Guidelines on the management of stable angina pectoris: executive summary. Eur Heart J 2006:27:1341-81.

22 The Joint European Society of Cardiology/American College of Cardiology Committee for the Redefinition of Myocardial Infarction. Myocardial infarction redefined-a consensus document of the Joint European Society of Cardiology/American College of Cardiology Committee for the Redefinition of Myocardial Infarction. Eur Heart J 2000;21:1502-13.

23 Thygesen K, Alpert JS, White HD. Universal definition of myocardial infarction. Eur Heart J 2007;28:2525-38.

24 Eldrup N, Sillesen H, Prescott E, Nordestgaard BG. Ankle brachial index, C-reactive protein, and central augmentation index to identify individuals with severe atherosclerosis. Eur Heart J 2006;27:316-22.

25 Criqui MH, Langer RD, Fronek A, Feigelson HS, Klauber MR, McCann TJ, et al. Mortality over a period of 10 years in patients with peripheral arterial disease. N Engl J Med 1992;326:381-6.

26 Murabito JM, Evans JC, Larson MG, Nieto K, Levy D, Wilson PW. The ankle-brachial index in the elderly and risk of stroke, coronary disease, and death: the Framingham Study. Arch Intern Med 2003;163:1939-42.

27 Newman AB, Shemanski L, Manolio TA, Cushman M, Mittelmark M, Polak JF, et al. Ankle-arm index as a predictor of cardiovascular disease and mortality in the Cardiovascular Health Study. Arterioscler Thromb Vasc Biol 1999:19:538-45.

28 Friedewald WT, Levy RI, Fredrickson DS. Estimation of the concentration of low-density lipoprotein cholesterol in plasma, without use of the preparative ultracentrifuge. Clin Chem 1972;18:499-502

29 Kamstrup PR, Benn M, Tybjaerg-Hansen A, Nordestgaard BG. Extreme lipoprotein(a) levels and risk of myocardial infarction in the general population: the Copenhagen City Heart Study. Circulation 2008:117:176-84.

30 Randomised trial of cholesterol lowering in 4444 patients with coronary heart disease: the Scandinavian Simvastatin Survival Study (4S). Lancet 1994;344:1383-9.

31 Langsted A, Freiberg JJ, Tybjærg-Hansen A, Schnohr P, Jensen GB, Nordestgaard BG. Nonfasting cholesterol and triglycerides and association with risk of myocardial infarction and total mortality: the Copenhagen City Heart Study with 31 years of follow-up. J Intern Med 2011;270:65-75.

32 Menotti A, Mariotti S, Seccareccia F, Torsello S, Dima F. Determinants of all causes of death in samples of Italian middle-aged men followed up for 25 years. $J$ Epidemiol Community Health 1987;41:243-50.

33 Menotti A, Giampaoli S, Seccareccia F. The relationship of cardiovascular risk factors measured at different ages to prediction of all-cause mortality and longevity. Arch Gerontol Geriatr 1998;26:99-111.

34 Douste-Blazy P, Marcel YL, Cohen L, Giroux JM, Davignon J. Increased frequency of Apo E-ND phenotype and hyperapobeta-lipoproteinemia in normolipidemic subjects with xanthelasmas of the eyelids. Ann Intern Med 1982;96:164-9.

35 National Cholesterol Education Program Expert Panel on Detection, Evaluation, and Treatment of High Blood Cholesterol in Adults. Third report of the NCEP Expert Panel on Detection, Evaluation, and Treatment of High Blood Cholesterol in Adults (Adult Treatment Panel III)-final report. Circulation 2002;106:3143-421.

Accepted: 14 July 2011

\section{Cite this as: BMJ 2011;343:d5497}

This is an open-access article distributed under the terms of the Creative Commons Attribution Non-commercial License, which permits use, distribution, and reproduction in any medium, provided the original work is properly cited, the use is non commercial and is otherwise in compliance with the license. See: http://creativecommons.org/licenses/bync/2.0/ and http://creativecommons.org/licenses/by-nc/2.0/legalcode. 


\section{Tables}

Table 1| Baseline characteristics of people from general population with and without xanthelasmata and with and without arcus corneae. Values are numbers (percentages) unless stated otherwise

\begin{tabular}{|c|c|c|c|c|}
\hline \multirow[b]{2}{*}{ Characteristic } & \multicolumn{2}{|c|}{ Xanthelasmata } & \multicolumn{2}{|c|}{ Arcus corneae } \\
\hline & Yes & No & Yes & No \\
\hline Observations & $563(4.4)$ & $12182(95.6)$ & $3159(24.8)$ & $9586(75.2)$ \\
\hline Median (interquartile range) age (years) & $57(50-64)^{*}$ & $53(44-60)$ & $61(55-67)^{*}$ & $50(41-58)$ \\
\hline Female sex & $305(54)$ & $6537(54)$ & $1375(44)^{*}$ & $5467(57)$ \\
\hline $\begin{array}{l}\text { Median (interquartile range) total cholesterol } \\
(\mathrm{mmol} / \mathrm{L})\end{array}$ & $6.2(5.6-7.2)^{*}$ & $6.0(5.2-6.8)$ & $6.3(5.6-7.1)^{\star}$ & $5.9(5.2-6.7)$ \\
\hline $\begin{array}{l}\text { Median (interquartile range) triglycerides } \\
(\mathrm{mmol} / \mathrm{L})\end{array}$ & $1.6(1.2-2.3)^{*}$ & $1.4(1.0-2.1)$ & $1.5(1.1-2.2)^{\star}$ & $1.4(1.0-2.0)$ \\
\hline $\begin{array}{l}\text { Median (interquartile range) body mass index } \\
\left(\mathrm{kg} / \mathrm{m}^{2}\right)\end{array}$ & $26(23-28)^{*}$ & $25(22-27)$ & $25(23-28)^{*}$ & $24(22-27)$ \\
\hline Hypertension† & $322(57)^{*}$ & $5858(48)$ & $1963(62)^{*}$ & $4217(44)$ \\
\hline Diabetes mellitus $\ddagger$ & $20(4)$ & $338(3)$ & $140(4)^{\star}$ & $218(2)$ \\
\hline Active smoker & $383(68) \S$ & $7673(63)$ & $2052(65) \S$ & $6004(63)$ \\
\hline $\begin{array}{l}\text { Median (interquartile range) pack years' } \\
\text { smokingף }\end{array}$ & $15(0-30)^{*}$ & $10(0-25)$ & $15(0-33)^{*}$ & $10(0-23)$ \\
\hline Regular alcohol consumer ${ }^{* *}$ & $272(48)$ & $6345(52)$ & $1697(54) \S$ & $4920(51)$ \\
\hline Physically inactive †† & $450(80) \S$ & $8937(73)$ & $2378(75) \S$ & $7009(73)$ \\
\hline Postmenopausal & $230(75) \S$ & $4331(66)$ & $1269(92)^{*}$ & $3292(60)$ \\
\hline Hormonal replacement therapy & $56(24)$ & $964(22)$ & $216(17)^{*}$ & $804(24)$ \\
\hline Lipid lowering treatment & 0 & 0 & 0 & 0 \\
\hline Family history of ischaemic vascular diseasełł & $192(46)$ & $4113(42)$ & $1021(44)$ & $3092(42)$ \\
\hline Education $<8$ years & $322(57)^{*}$ & $5730(47)$ & $1798(57)^{*}$ & $4254(44)$ \\
\hline Income $<10000 \mathrm{DKK} /$ month & $457(81)$ & $9736(80)$ & $2659(84)^{*}$ & $7534(79)$ \\
\hline
\end{tabular}

${ }^{*} \mathrm{P}<0.001$ by Mann-Whitney $\mathrm{U}$ test or Pearson $\mathrm{X}^{2}$ test.

†Use of antihypertensive drugs, systolic blood pressure $\geq 140 \mathrm{~mm} \mathrm{Hg}$, or diastolic blood pressure $\geq 90 \mathrm{~mm} \mathrm{Hg}$

$\ddagger$ Self reported disease, use of insulin or oral hypoglycaemic agents, or non-fasting plasma glucose concentrations $>11 \mathrm{mmol} / \mathrm{L}$ ( $>198 \mathrm{mg} / \mathrm{dL}$ ).

$\S \mathrm{P}<0.05$ by Mann-Whitney $U$ test or Pearson $x^{2}$ test.

$\uparrow$ Accumulated smoking exposure calculated from questionnaires.

${ }^{* *}$ At least twice weekly.

††Leisure time activity $<4$ hours weekly.

$\ddagger \ddagger A t$ least one parent with previous myocardial infarction or ischaemic stroke. 
Table 2| Hazard/odds ratios for ischaemic vascular disease, total death, and severe atherosclerosis (ankle brachial index $(\mathrm{ABI})<0.9 \mathrm{v} \geq 0.9$ ) by presence or absence of xanthelasmata

\begin{tabular}{|c|c|c|c|c|c|}
\hline \multirow[b]{2}{*}{ End point } & \multirow[b]{2}{*}{ No of participants } & \multirow[b]{2}{*}{ No of events } & \multirow{2}{*}{$\begin{array}{c}\text { Events } / 10000 \text { person } \\
\text { years }(95 \% \mathrm{Cl})\end{array}$} & \multicolumn{2}{|c|}{ Hazard/odds ratios* $(95 \% \mathrm{Cl})$} \\
\hline & & & & Age and sex adjusted & Multifactorially adjusted $\dagger$ \\
\hline \multicolumn{6}{|l|}{ Myocardial infarction: } \\
\hline No xanthelasmata & 12182 & 1749 & 65 (62 to 69$)$ & 1 & 1 \\
\hline Xanthelasmata & 563 & 123 & 121 (101 to 144$)$ & $1.67(1.39$ to 2.00$)$ & 1.48 (1.23 to 1.79$)$ \\
\hline \multicolumn{6}{|c|}{ Ischaemic heart disease: } \\
\hline No xanthelasmata & 12182 & 3482 & 134 (130 to 139$)$ & 1 & 1 \\
\hline Xanthelasmata & 563 & 217 & 226 (197 to 258 ) & $1.52(1.32$ to 1.74$)$ & $1.39(1.20$ to 1.60$)$ \\
\hline \multicolumn{6}{|l|}{ Ischaemic stroke: } \\
\hline No xanthelasmata & 12182 & 1431 & 53 (51 to 56$)$ & 1 & 1 \\
\hline Xanthelasmata & 563 & 67 & $64(49$ to 81$)$ & $1.05(0.82$ to 1.34$)$ & 0.94 (0.73 to 1.21$)$ \\
\hline \multicolumn{6}{|c|}{$\begin{array}{l}\text { Ischaemic cerebrovascular } \\
\text { disease: }\end{array}$} \\
\hline No xanthelasmata & 12182 & 1738 & 65 (62 to 68$)$ & 1 & 1 \\
\hline Xanthelasmata & 563 & 77 & 74 (59 to 93 ) & 1.00 (0.79 to 1.25$)$ & 0.91 (0.72 to 1.15$)$ \\
\hline \multicolumn{6}{|l|}{ Total deaths: } \\
\hline No xanthelasmata & 12182 & 8061 & 293 (287 to 300$)$ & 1 & 1 \\
\hline Xanthelasmata & 563 & 446 & 414 (376 to 454$)$ & $1.25(1.14$ to 1.38$)$ & 1.14 (1.04 to 1.26$)$ \\
\hline \multicolumn{6}{|c|}{$\begin{array}{l}\text { Severe atherosclerosis }(\mathrm{ABI}<0.9 \\
v \geq 0.9 \text { ): }\end{array}$} \\
\hline No xanthelasmata & 2698 & 618 & - & 1 & 1 \\
\hline Xanthelasmata & 75 & 29 & - & $1.76(1.08$ to 2.85$)$ & 1.69 (1.03 to 2.79$)$ \\
\hline
\end{tabular}

*Hazard ratios for myocardial infarction, ischaemic heart disease, ischaemic stroke, ischaemic cerebrovascular disease, and total death from Copenhagen City Heart Study 1976-8 examination ( $\mathrm{n}=12745$; follow-up up to 33 years, mean follow-up 22 years); odds ratios for severe atherosclerosis $(A B I<0.9 v \geq 0.9)$ from Copenhagen City Heart Study 2001-3 examination.

†Adjusted for age, sex, total cholesterol, triglycerides, body mass index, hypertension, diabetes, pack years' smoking, alcohol consumption, lipid lowering treatment, physical inactivity, education, income, family history of ischaemic vascular disease, and in women also for postmenopausal status and hormonal replacement therapy. 
Table 3| Hazard/odds ratios for ischaemic vascular disease, total death, and severe atherosclerosis (ankle brachial index $(\mathrm{ABI})<0.9 \mathrm{v} \geq 0.9$ ) by presence or absence of arcus corneae

\begin{tabular}{|c|c|c|c|c|c|}
\hline \multirow[b]{2}{*}{ End point } & \multirow[b]{2}{*}{ No of participants } & \multirow[b]{2}{*}{ No of events } & \multirow{2}{*}{$\begin{array}{c}\text { Events } / 10000 \text { person } \\
\text { years }(95 \% \mathrm{Cl})\end{array}$} & \multicolumn{2}{|c|}{ Hazard/odds ratios* $(95 \% \mathrm{Cl})$} \\
\hline & & & & Age and sex adjusted & Multifactorially adjusted $\dagger$ \\
\hline \multicolumn{6}{|l|}{ Myocardial infarction: } \\
\hline No arcus corneae & 9586 & 1289 & 57 (54 to 61$)$ & 1 & 1 \\
\hline Arcus corneae & 3159 & 583 & $110(101$ to 120$)$ & $1.15(1.04$ to 1.27$)$ & $0.97(0.88$ to 1.08$)$ \\
\hline \multicolumn{6}{|c|}{ Ischaemic heart disease: } \\
\hline No arcus corneae & 9586 & 2513 & 115 (111 to 120$)$ & 1 & 1 \\
\hline Arcus corneae & 3159 & 1186 & 236 (223 to 250 ) & $1.18(1.10$ to 1.27$)$ & 1.06 (0.98 to 1.14$)$ \\
\hline \multicolumn{6}{|l|}{ Ischaemic stroke: } \\
\hline No arcus corneae & 9586 & 1057 & 47 (44 to 50$)$ & 1 & 1 \\
\hline Arcus corneae & 3159 & 441 & $83(76$ to 91$)$ & 0.98 (0.87 to 1.10$)$ & 0.90 (0.80 to 1.01$)$ \\
\hline \multicolumn{6}{|c|}{$\begin{array}{l}\text { Ischaemic cerebrovascular } \\
\text { disease: }\end{array}$} \\
\hline No arcus corneae & 9586 & 1285 & 57 (54 to 60 ) & 1 & 1 \\
\hline Arcus corneae & 3159 & 530 & 101 (93 to 110$)$ & $0.98(0.89$ to 1.09$)$ & $0.90(0.81$ to 1.00$)$ \\
\hline \multicolumn{6}{|l|}{ Total deaths: } \\
\hline No arcus corneae & 9586 & 5710 & 247 (241 to 254$)$ & 1 & 1 \\
\hline Arcus corneae & 3159 & 2797 & 510 (491 to 529$)$ & $1.09(1.04$ to 1.14$)$ & $1.02(0.97$ to 1.07$)$ \\
\hline \multicolumn{6}{|c|}{$\begin{array}{l}\text { Severe atherosclerosis }(\mathrm{ABI}<0.9 \\
v \geq 0.9) \text { : }\end{array}$} \\
\hline No arcus corneae & 2524 & 562 & - & 1 & 1 \\
\hline Arcus corneae & 249 & 85 & - & $1.27(0.94$ to 1.70$)$ & $1.25(0.92$ to 1.70$)$ \\
\hline
\end{tabular}

*Hazard ratios for myocardial infarction, ischaemic heart disease, ischaemic stroke, ischaemic cerebrovascular disease, and total death from Copenhagen City Heart Study 1976-8 examination ( $n=12745$; follow-up up to 33 years, mean follow-up 22 years); odds ratios for severe atherosclerosis (ABI <0.9 $v \geq 0.9)$ from Copenhagen City Heart Study 2001-3 examination.

†Adjusted for age, sex, total cholesterol, triglycerides, body mass index, hypertension, diabetes, pack years' smoking, alcohol consumption, lipid lowering treatment, physical inactivity, education, income, family history of ischaemic vascular disease, and in women also for postmenopausal status and hormonal replacement therapy. 
Table 4| Hazard/odds ratios for ischaemic vascular disease, total death, and severe atherosclerosis (ankle brachial index $(\mathrm{ABI})<0.9 \mathrm{v} \geq 0.9$ ) by presence of xanthelasmata, arcus corneae, or both

\begin{tabular}{|c|c|c|c|c|c|}
\hline \multirow[b]{2}{*}{ End point } & \multirow{2}{*}{$\begin{array}{l}\text { No of } \\
\text { participants }\end{array}$} & \multirow[b]{2}{*}{ No of events } & \multirow{2}{*}{$\begin{array}{c}\text { Events } / 10000 \text { person } \\
\text { years }(95 \% \mathrm{Cl})\end{array}$} & \multicolumn{2}{|c|}{ Hazard/odds ratios* $(95 \% \mathrm{Cl})$} \\
\hline & & & & Age and sex adjusted & Multifactorially adjusted $†$ \\
\hline \multicolumn{6}{|l|}{ Myocardial infarction: } \\
\hline $\begin{array}{l}\text { Neither xanthelasmata nor arcus } \\
\text { corneae }\end{array}$ & 9202 & 1211 & 56 (53 to 59$)$ & 1 & 1 \\
\hline Only arcus corneae & 2980 & 538 & 107 (98 to 117$)$ & $1.14(1.03$ to 1.27$)$ & $0.97(0.87$ to 1.08$)$ \\
\hline Only xanthelasmata & 384 & 78 & $104(82$ to 130$)$ & $1.67(1.33$ to 2.11$)$ & $1.43(1.14$ to 1.81$)$ \\
\hline $\begin{array}{l}\text { Both xanthelasmata and arcus } \\
\text { corneae }\end{array}$ & 179 & 45 & 167 (122 to 224$)$ & 1.86 (1.38 to 2.50$)$ & $1.47(1.09$ to 1.99$)$ \\
\hline \multicolumn{6}{|l|}{ Ischaemic heart disease: } \\
\hline $\begin{array}{l}\text { Neither xanthelasmata nor arcus } \\
\text { corneae }\end{array}$ & 9202 & 2383 & 113 (108 to 117$)$ & 1 & 1 \\
\hline Only arcus corneae & 2980 & 1099 & 230 (217 to 244$)$ & 1.17 (1.08 to 1.25$)$ & 1.05 (0.97 to 1.13$)$ \\
\hline Only xanthelasmata & 384 & 130 & $182(152$ to 216$)$ & 1.45 (1.22 to 1.73$)$ & $1.32(1.10$ to 1.58$)$ \\
\hline $\begin{array}{l}\text { Both xanthelasmata and arcus } \\
\text { corneae }\end{array}$ & 179 & 87 & 353 (283 to 436$)$ & 1.85 (1.50 to 2.30$)$ & $1.56(1.25$ to 1.94$)$ \\
\hline \multicolumn{6}{|l|}{ Ischaemic stroke: } \\
\hline $\begin{array}{l}\text { Neither xanthelasmata nor arcus } \\
\text { corneae }\end{array}$ & 9202 & 1014 & 47 (44 to 49$)$ & 1 & 1 \\
\hline Only arcus corneae & 2980 & 417 & 83 (75 to 91$)$ & $0.98(0.87$ to 1.10$)$ & $0.90(0.80$ to 1.01$)$ \\
\hline Only xanthelasmata & 384 & 43 & 56 (40 to 75$)$ & $1.04(0.77$ to 1.42$)$ & $0.92(0.67$ to 1.26$)$ \\
\hline $\begin{array}{l}\text { Both xanthelasmata and arcus } \\
\text { corneae }\end{array}$ & 179 & 24 & 86 (55 to 128$)$ & 1.04 (0.69 to 1.56$)$ & $0.87(0.57$ to 1.31$)$ \\
\hline \multicolumn{6}{|l|}{ Ischaemic cerebrovascular disease: } \\
\hline $\begin{array}{l}\text { Neither xanthelasmata nor arcus } \\
\text { corneae }\end{array}$ & 9202 & 1235 & 57 (54 to 60$)$ & 1 & 1 \\
\hline Only arcus corneae & 2980 & 503 & $101(93$ to 111$)$ & 0.98 (0.88 to 1.09$)$ & $0.90(0.80$ to 1.00$)$ \\
\hline Only xanthelasmata & 384 & 50 & 66 (49 to 86$)$ & $1.00(0.76$ to 1.33$)$ & $0.89(0.67$ to 1.19$)$ \\
\hline $\begin{array}{l}\text { Both xanthelasmata and arcus } \\
\text { corneae }\end{array}$ & 179 & 27 & 98 (65 to 143$)$ & $0.98(0.67$ to 1.43$)$ & 0.86 (0.58 to 1.26$)$ \\
\hline \multicolumn{6}{|l|}{ Total deaths: } \\
\hline $\begin{array}{l}\text { Neither xanthelasmata nor arcus } \\
\text { corneae }\end{array}$ & 9202 & 5426 & 243 (237 to 250$)$ & 1 & 1 \\
\hline Only arcus corneae & 2980 & 2635 & 507 (488 to 527$)$ & 1.09 (1.04 to 1.15$)$ & $1.02(0.97$ to 1.07$)$ \\
\hline Only xanthelasmata & 384 & 284 & 359 (318 to 403$)$ & $1.29(1.14$ to 1.45$)$ & $1.19(1.05$ to 1.34$)$ \\
\hline $\begin{array}{l}\text { Both xanthelasmata and arcus } \\
\text { corneae }\end{array}$ & 179 & 162 & 564 (481 to 658 ) & $1.29(1.10$ to 1.51$)$ & 1.09 (0.93 to 1.28$)$ \\
\hline \multicolumn{6}{|l|}{$\begin{array}{l}\text { Severe atherosclerosis }(\mathrm{ABI}<0.9 v \\
\geq 0.9) \text { : }\end{array}$} \\
\hline $\begin{array}{l}\text { Neither xanthelasmata nor arcus } \\
\text { corneae }\end{array}$ & 2459 & 538 & - & 1 & 1 \\
\hline Only arcus corneae & 239 & 80 & - & $1.26(0.93$ to 1.70$)$ & $1.23(0.90$ to 1.68$)$ \\
\hline Only xanthelasmata & 65 & 24 & - & 1.73 (1.03 to 2.93$)$ & 1.51 (0.87 to 2.63$)$ \\
\hline $\begin{array}{l}\text { Both xanthelasmata and arcus } \\
\text { corneae }\end{array}$ & 10 & 5 & - & 2.34 (0.67 to 8.21$)$ & $2.75(0.75$ to 10.1$)$ \\
\hline
\end{tabular}

*Hazard ratios for myocardial infarction, ischaemic heart disease, ischaemic stroke, ischaemic cerebrovascular disease, and total death from Copenhagen City Heart Study 1976-8 examination ( $n=12745$; follow-up up to 33 years, mean follow-up 22 years); odds ratios for severe atherosclerosis (ABI <0.9 $v \geq 0.9$ ) from Copenhagen City Heart Study 2001-3 examination.

†Adjusted for age, sex, total cholesterol, triglycerides, body mass index, hypertension, diabetes, pack years' smoking, alcohol consumption, lipid lowering treatment, physical inactivity, education, income, family history of ischaemic vascular disease, and in women also for postmenopausal status and hormonal replacement therapy. 
Table 5| Ankle brachial index ( $\mathrm{ABI}$ ) as continuous variable or proportion with $\mathrm{ABI}<0.9$ (severe atherosclerosis) in people with or without baseline xanthelasmata or arcus corneae at 2001-3 examination of Copenhagen City Heart Study

\begin{tabular}{lccc} 
Group & No of participants & Mean (SE) ankle brachial index No (\%) of participants with ABI <0.9 \\
No xanthelasmata & 2698 & $0.99(0.003)$ & $618(23)$ \\
\hline Xanthelasmata & 75 & $0.93(0.02)^{\star}$ & $29(39)^{\star}$ \\
\hline No arcus corneae & 2524 & $0.99(0.003)$ & $562(22)$ \\
\hline Arcus corneae & 249 & $0.95(0.01)^{\star}$ & $85(34)^{\star}$ \\
\hline
\end{tabular}

${ }^{*} \mathrm{P}<0.01$ by Mann-Whitney $\mathrm{U}$ test or Pearson $\mathrm{X}^{2}$ test when comparing people with or without xanthelasmata or arcus corneae. 
Table 6| Absolute 10 year risk of myocardial infarction, ischaemic heart disease, and total death in Copenhagen City Heart Study ${ }^{\star}$ in people with and without xanthelasmata stratified by sex and 10 year age groups. Values are percentages $(95 \%$ confidence intervals)

\begin{tabular}{|c|c|c|c|c|c|c|c|c|c|c|}
\hline & \multicolumn{5}{|c|}{ Women (10 year age groups) } & \multicolumn{5}{|c|}{ Men (10 year age groups) } \\
\hline & $<40$ & $40-49$ & $50-59$ & $60-69$ & $70-79$ & $<40$ & $40-49$ & $50-59$ & $60-69$ & $70-79$ \\
\hline \multicolumn{11}{|c|}{ Myocardial infarction } \\
\hline $\begin{array}{l}\text { No } \\
\text { xanthelasmata }\end{array}$ & $\begin{array}{c}1.2(1.0 \text { to } \\
1.5)\end{array}$ & $\begin{array}{c}2.9(2.6 \text { to } \\
3.3)\end{array}$ & $\begin{array}{l}5.2(4.8 \text { to } \\
5.7)\end{array}$ & $\begin{array}{c}7.8(7.1 \text { to } \\
8.6)\end{array}$ & $\begin{array}{c}9.2(7.6 \text { to } \\
11) \dagger\end{array}$ & $\begin{array}{c}2.7 \text { ( } 2.2 \text { to } \\
3.2)\end{array}$ & $\begin{array}{c}6.3(5.6 \text { to } \\
7.0)\end{array}$ & $\begin{array}{c}11 \text { (10 to } \\
12)\end{array}$ & $\begin{array}{c}16(15 \text { to } \\
18)\end{array}$ & $\begin{array}{c}19(16 \text { to } \\
23) \dagger\end{array}$ \\
\hline Xanthelasmata & $\begin{array}{c}1.9 \text { (1.5 to } \\
2.5) \uparrow\end{array}$ & $\begin{array}{c}4.5 \text { (3.7 to } \\
5.5) \text { ฯ }\end{array}$ & $\begin{array}{c}8.1(6.7 \text { to } \\
9.7) \S\end{array}$ & $\begin{array}{c}12(9.9 \text { to } \\
14) \S\end{array}$ & $\begin{array}{c}14 \text { (11 to } \\
18) \neq \mathbb{~}\end{array}$ & $\begin{array}{c}4.1 \text { (3.2 to } \\
5.3) 9\end{array}$ & $\begin{array}{c}9.6(7.9 \text { to } \\
12) \rrbracket\end{array}$ & $\begin{array}{c}17 \text { (14 to } \\
20) \S\end{array}$ & $\begin{array}{c}25(21 \text { to } \\
29) \S\end{array}$ & $\begin{array}{c}28 \text { (23 to } \\
35) \neq \rrbracket\end{array}$ \\
\hline \multicolumn{11}{|c|}{ Ischaemic heart disease } \\
\hline $\begin{array}{l}\text { No } \\
\text { xanthelasmata }\end{array}$ & $\begin{array}{c}3.1 \text { (2.8 to } \\
3.6)\end{array}$ & $\begin{array}{c}6.9(6.3 \text { to } \\
7.4)\end{array}$ & 11 (10 to 12$)$ & 18 (16 to 19$)$ & $\begin{array}{c}27(24 \text { to } \\
29) \dagger\end{array}$ & $\begin{array}{c}5.4(4.8 \text { to } \\
6.1)\end{array}$ & 12 (11 to 12$)$ & $\begin{array}{c}18(17 \text { to } \\
19)\end{array}$ & $\begin{array}{c}28(27 \text { to } \\
30)\end{array}$ & $\begin{array}{c}41 \text { (38 to } \\
45) \dagger\end{array}$ \\
\hline Xanthelasmata & $\begin{array}{c}4.4 \text { (3.7 to } \\
5.3) 9\end{array}$ & $\begin{array}{c}9.5(8.2 \text { to } \\
11) \S\end{array}$ & $\begin{array}{c}15 \text { (13 to } \\
17) \S\end{array}$ & $\begin{array}{c}24(21 \text { to } \\
27) \S\end{array}$ & $\begin{array}{c}35 \text { (31 to } \\
40)+9\end{array}$ & $\begin{array}{c}7.5 \text { (6.3 to } \\
9.0) 9\end{array}$ & $\begin{array}{c}16(14 \text { to } \\
18) \S\end{array}$ & $\begin{array}{c}25 \text { (22 to } \\
28) \S\end{array}$ & $\begin{array}{c}38 \text { (33 to } \\
42) \S\end{array}$ & $\begin{array}{c}53(47 \text { to } \\
59)+\S\end{array}$ \\
\hline \multicolumn{11}{|l|}{ Overall death } \\
\hline $\begin{array}{l}\text { No } \\
\text { xanthelasmata }\end{array}$ & $\begin{array}{c}5.1 \text { (4.6 to } \\
5.7)\end{array}$ & $14(14$ to 15$)$ & 25 (24 to 26$)$ & 38 (37 to 40$)$ & $\begin{array}{c}51 \text { (48 to } \\
54) \dagger\end{array}$ & $\begin{array}{c}7.3(6.6 \text { to } \\
8.1)\end{array}$ & 20 (19 to 21$)$ & $\begin{array}{c}34 \text { (33 to } \\
36)\end{array}$ & $\begin{array}{c}50 \text { (49 to } \\
52)\end{array}$ & $\begin{array}{c}64(62 \text { to } \\
67) \dagger\end{array}$ \\
\hline Xanthelasmata & $\begin{array}{c}6.0(5.2 \text { to } \\
6.9)\end{array}$ & $\begin{array}{c}17(15 \text { to } \\
18) \S\end{array}$ & $\begin{array}{c}29 \text { (27 to } \\
32) \uparrow\end{array}$ & $\begin{array}{c}44 \text { (40 to } \\
47) \uparrow\end{array}$ & $\begin{array}{c}57 \text { (53 to } \\
61)+9\end{array}$ & $\begin{array}{c}8.6(7.5 \text { to } \\
9.8)\end{array}$ & $\begin{array}{c}23 \text { (21 to } \\
25) 9\end{array}$ & $\begin{array}{c}39 \text { (36 to } \\
42) \uparrow\end{array}$ & $\begin{array}{c}56 \text { (53 to } \\
60) \uparrow\end{array}$ & $\begin{array}{c}70(66 \text { to } \\
75)+\uparrow\end{array}$ \\
\hline
\end{tabular}

*From 1976-8 examination ( $\mathrm{n}=12$ 745; follow-up up to 33 years, mean follow-up 22 years).

$\dagger P<0.001$ when testing for trend in absolute 10 year risk across age groups.

$\ddagger \mathrm{P}<0.05$ when testing for trend in absolute 10 year risk across age groups.

$\S \mathrm{P}<0.001$ when comparing people with and without baseline xanthelasmata.

$\llbracket \mathrm{P}<0.05$ when comparing people with and without baseline xanthelasmata. 
Figures
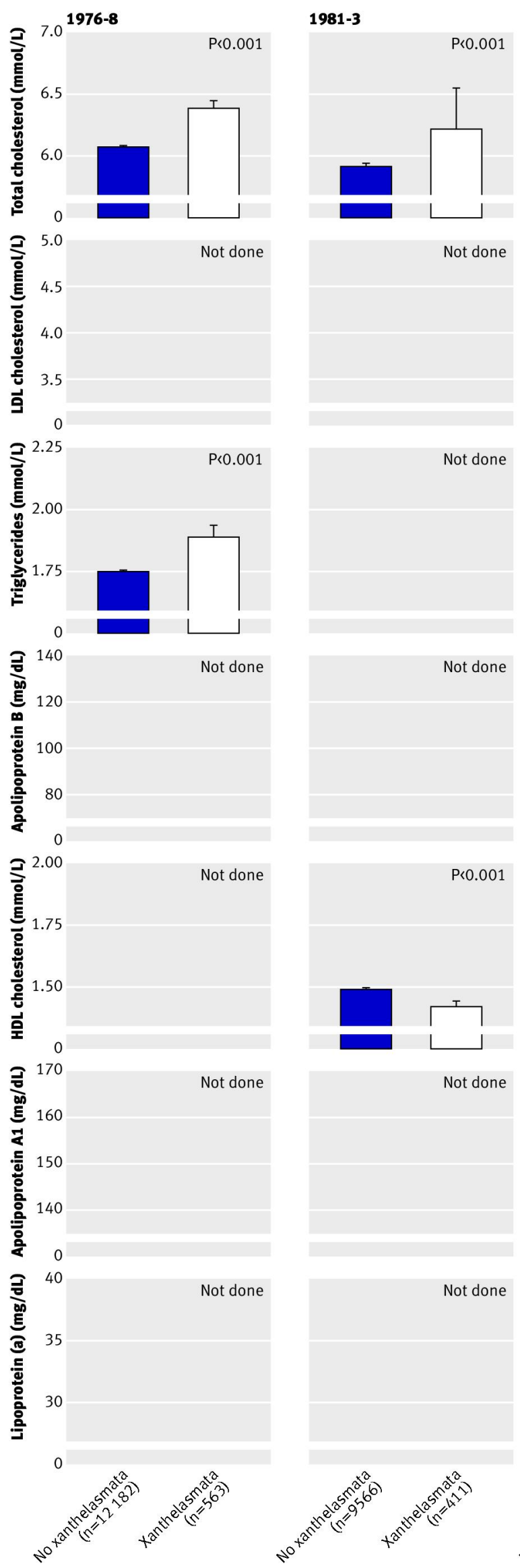

Not done

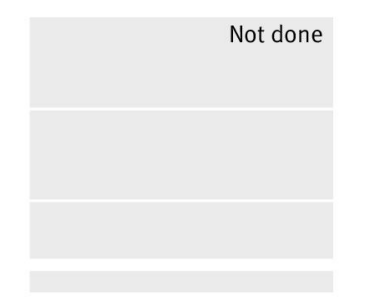

Not done

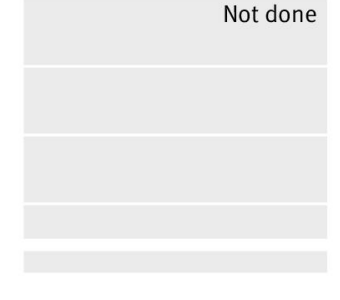

P<0.001

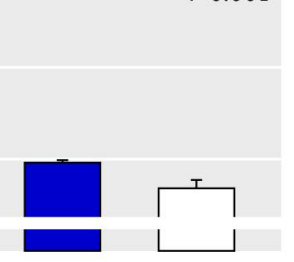

Not done

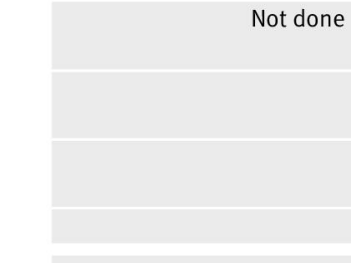

Not done
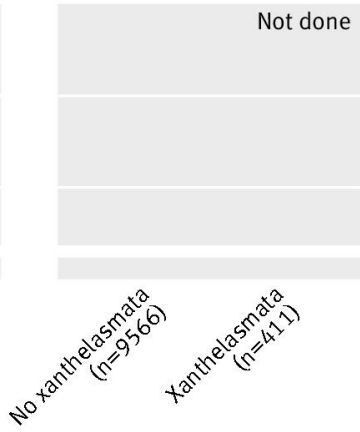

1991-4

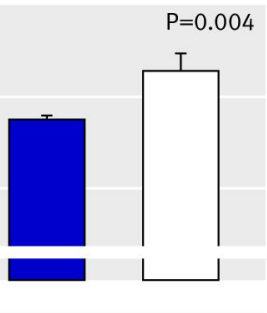

$P=0.001$

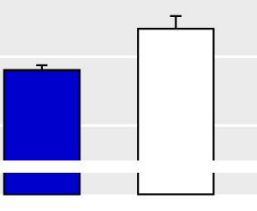

2001-3

$P=0.33$

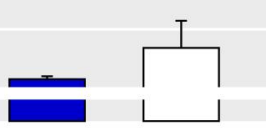

$P=0.03$

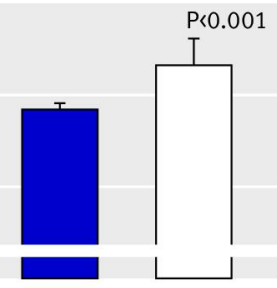

P 0.001

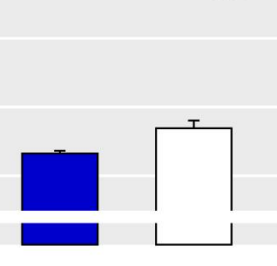

$P=0.004$

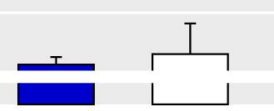

$\mathrm{P}=0.02$

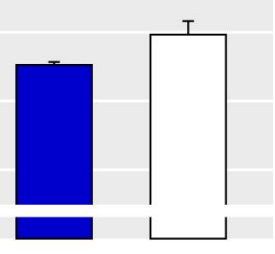

$\mathrm{P}=0.11$
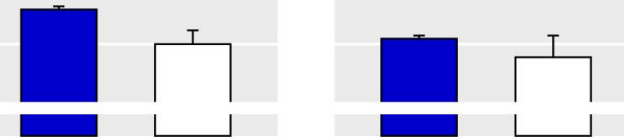

$P=0.04$

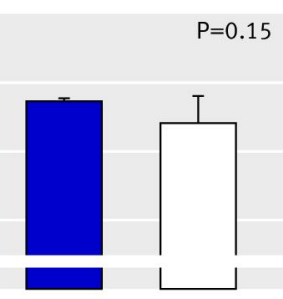

$P=0.84$

$P=0.30$
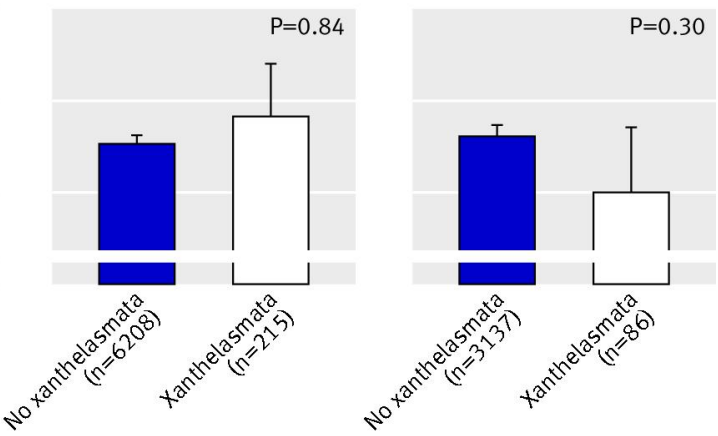
Fig 1 Mean plasma concentrations of lipids, lipoproteins, and apolipoproteins in people with or without baseline xanthelasmata at the 1976-8, 1981-3, 1991-3, and 2001-3 examinations of Copenhagen City Heart Study. Error bars represent standard errors of the mean. HDL=high density lipoprotein; LDL=low density lipoprotein. 


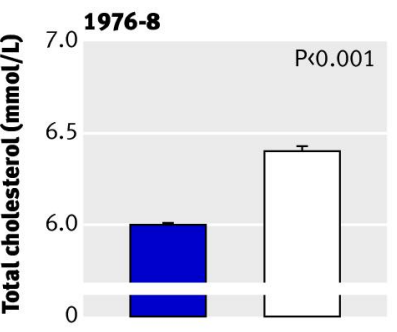

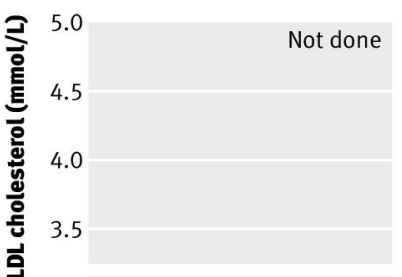

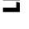
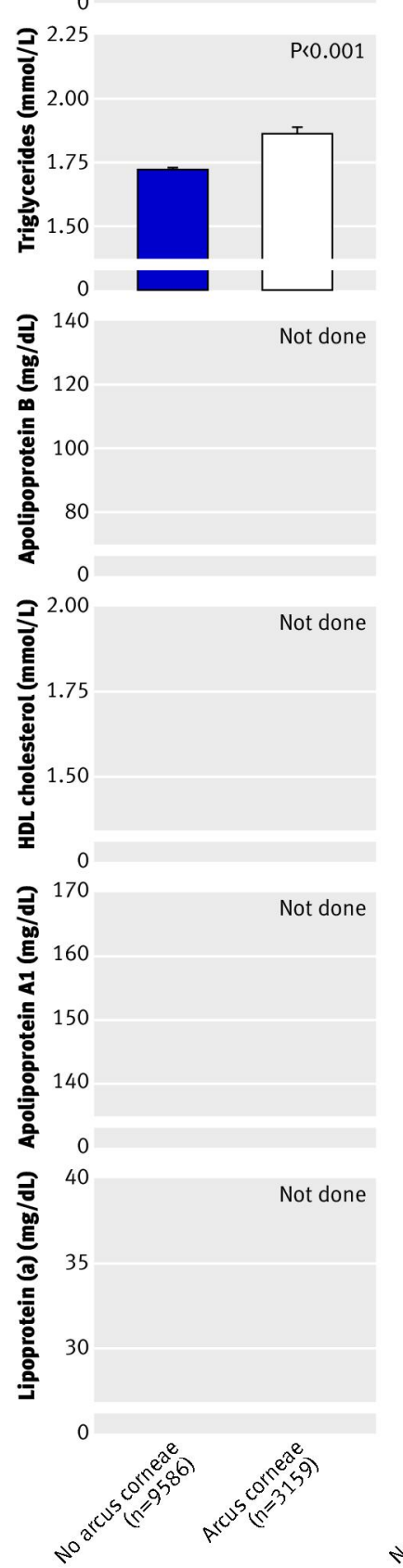

1981-3

P<0.001

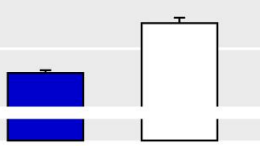

Not done

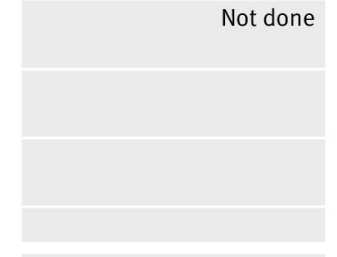

Not done

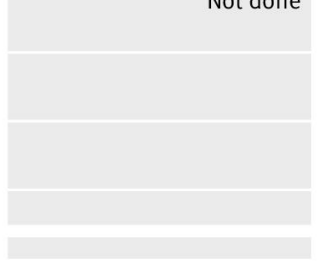

Not done

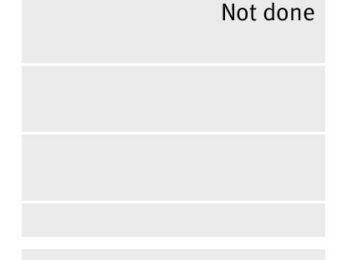

$P=0.28$

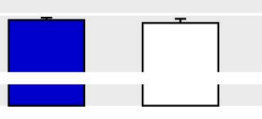

Not done

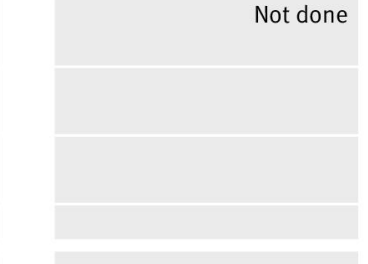

Not done
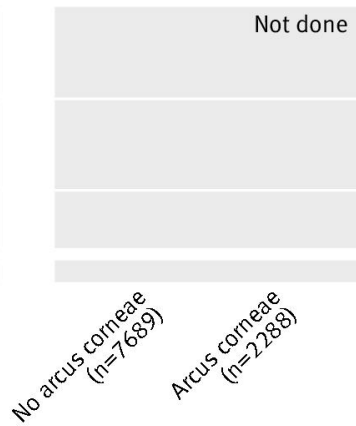

1991-4

$P<0.001$

2001-3
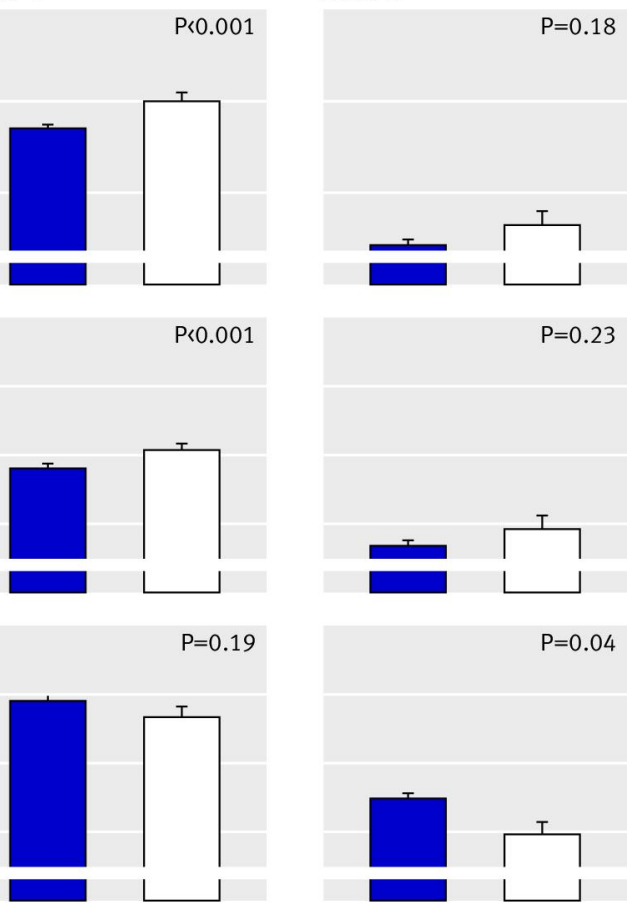

$P=0.19$

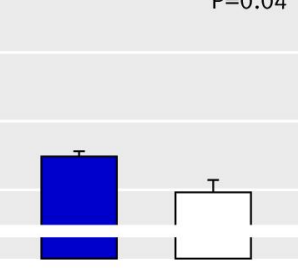

$\mathrm{P}=0.002$

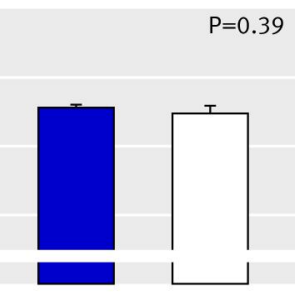

$P=0.41$

$P=0.06$

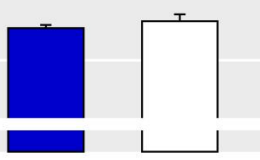

$P=0.90$

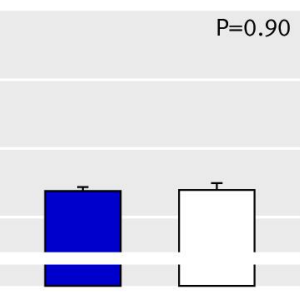

P<0.001

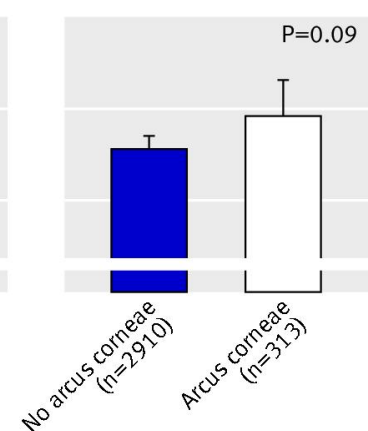

Fig 2 Mean plasma concentrations of lipids, lipoproteins, and apolipoproteins in people with or without baseline arcus corneae at the 1976-8, 1981-3, 1991-3, and 2001-3 examinations of Copenhagen City Heart Study. Error bars represent standard errors of the mean. $\mathrm{HDL}=$ high density lipoprotein; $\mathrm{LDL}=$ low density lipoprotein. 

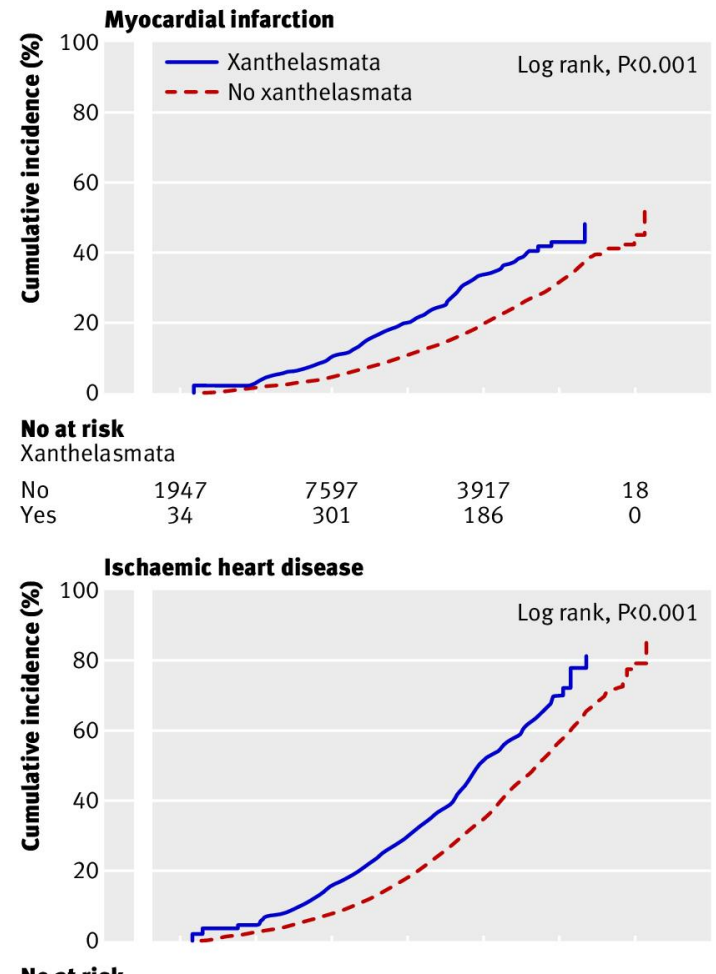

\section{No at risk}

Xanthelasmata
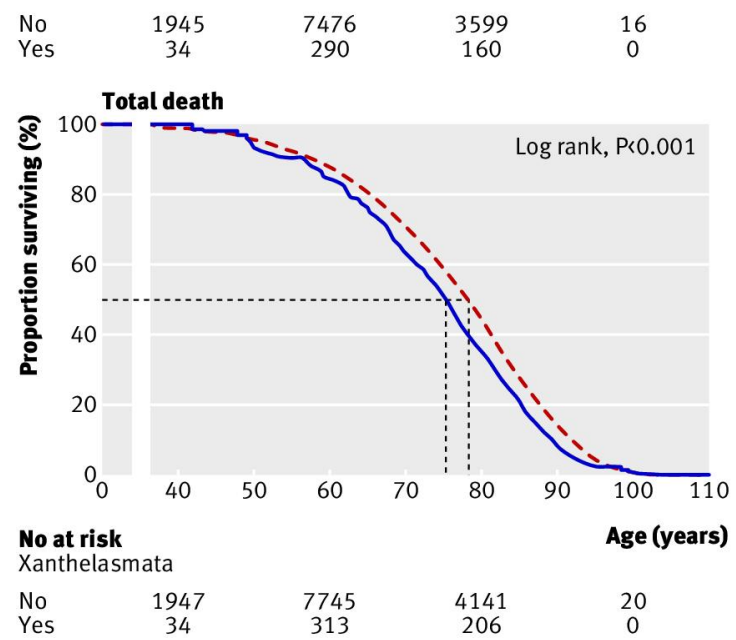

Fig 3 Cumulative incidences of myocardial infarction, ischaemic heart disease, and total death in Copenhagen City Heart Study in people with or without xanthelasmata. Dotted lines indicate median survival time in people with and without xanthelasmata 


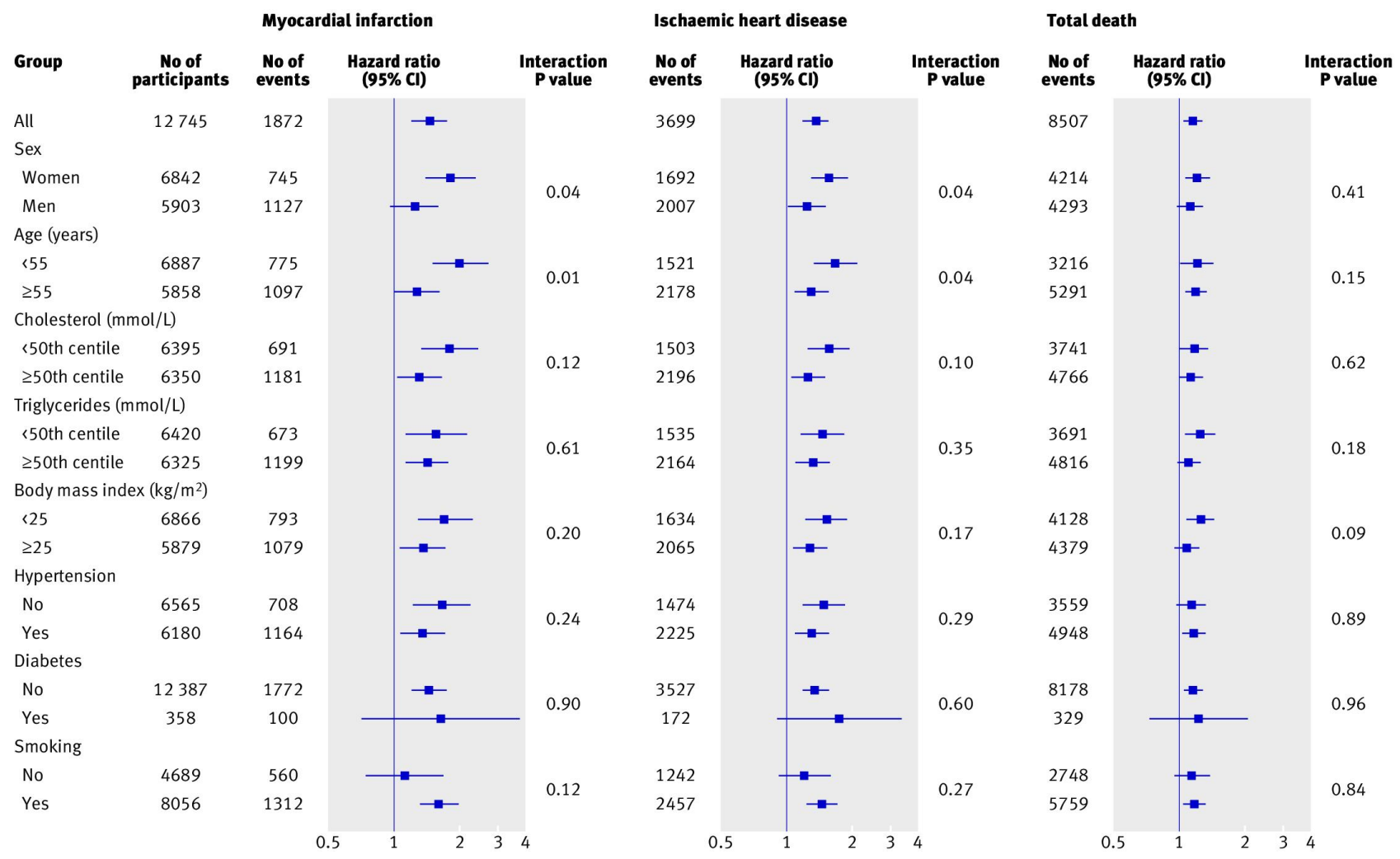

Fig 4 Risk of myocardial infarction, ischaemic heart disease, and total death in Copenhagen City Heart Study in people with versus those without xanthelasmata stratified by cardiovascular risk factors. Hazard ratios are from 1976-8 examination ( $n=12745$; follow-up up to 33 years, mean follow-up 22 years). Adjustment was for age, sex, total cholesterol, triglycerides, body mass index, hypertension, diabetes, pack years' smoking, alcohol consumption, physical inactivity, education, income, family history of ischaemic vascular disease, and in women also for postmenopausal status and hormonal replacement therapy. $P$ values are for interaction between presence or absence of xanthelasmata and cardiovascular risk factors on risk of myocardial infarction, ischaemic heart disease, and total death. Within strata of risk factors, people without xanthelasmata (reference group) have hazard ratio $=1$ and are not shown 